\title{
Inhaltsverzeichnis
}

\section{Fall Gegenstand}

Teil 1: Überblick über die Rechtsordnung in der Bundesrepublik

Deutschland . . . . . . . . . . . . . . 2

Nr. 1 Abgrenzung zwischen privatem und öffentlichem Recht . . . 2

Nr. 2 Gebiete des Privatrechts . . . . . . . . . . . 4

Nr. 3 Rechtsquellen . . . . . . . . . . . . . 6

Teil 2: Rechtssubjekte . . . . . . . . . . . . . 10

Nr. 4 Rechtsfähigkeit, Handlungsfähigkeit, Geschäftsfähigkeit . . . 10

Nr. 5 Deliktsfähigkeit . . . . . . : . . . . . . . . 11

Nr. 6 Parteifähigkeit, Prozeßfähigkeit; materielles und formelles Recht 12

Nr. 7 Juristische Personen, Organe . . . . . . . . . 14

Teil 3: Rechtsobjekte . . . . . . . . . . . . . 16

Nr. 8 Rechte und Sachen . . . . . . . . . . . . 16

Nr. 9 Persönlichkeitsrechte und Vermögensrechte . . . . . . 18

Nr. 10 Bewegliche und unbewegliche Sachen; wesentliche Bestandteile 20

Nr.11 Scheinbestandteile . . . . . . . . . . . . 26

Nr. 12 Erzeugnisse, Samen und Pflanzen . . . . . . . . 27

Teil 4: Rechtshandlungen . . . . . . . . . . . . . 29

Nr.13 Tathandlungen und Rechtsgeschäfte; juristische Arbeitsmethoden 29

Nr.14 inhalt der Willenserklärung . . . . . . . . . . 31

Nr. 15 Form der Willenserklärung . . . . . . . . . . 32

Nr. 16 Folgen eines FormverstoBes . . . . . . . . . . . 35

Nr. 17 Einseitige, empfangsbedürttige Willenserklärungen; Kündigung . 36

Nr. 18 Einseitige, nicht empfangsbedürftige Willenserklärungen;

Auslobung . . . . . . . . . . . . . . 37

Nr. 19 Mehrseitige Willenserklărungen; Antrag und Annahme . . . 38

Nr. 20 Schlüssiges Verhalten; Gutachtenaufbau . . . . . . . 39

Nr. 21 Schweigen im Rechtsverkehr; Gutachtenstil . . . . . . 42

Nr. 22 Schweigen unter Kaufleuten; Firma; Gutachtenstil . . . . 43

Nr. 23 Verzicht auf Annahme . . . . . . . . . . . 46

Nr. 24 Annahme durch schlüssiges Verhalten; Auftragsbestätigung . . 47

Nr. 25 Allgemeine Geschäftsbedingungen . . . . . . . . 48

Nr. 26 Bestätigungsschreiben . . . . . . . . . . . 49

Nr. 27 Vertragsänderung durch Rechnungsaufdrucke? . . . . . 50

Teil 5: Willensmängel . . . . . . . . . . . . . 51

Nr. 28 Erklärungsirrtum; Vertrauensinteresse . . . . . . . 51

Nr. 29 Erfüllungsinteresse $. \quad . \quad . \quad . \quad . \quad . \quad . \quad . \quad . \quad . \quad . \quad . \quad 54$ 
Nr. 30 Erfüllungsinteresse begrenzt Vertrauensinteresse . . . . 54

Nr. 31 Erfüllungsinteresse gleich Vertrauensinteresse . . . . . 55

Nr. 32 Inhaltsirrtum . . . . . . . . . . . . . . 55

Nr. 33 Eigenschaftsirrtum . . . . . . . . . . . . 57

Nr. 34 Motivirrtum . . . . . . . . . . . . . . 58

Nr. 35 Grundsätzliches zu den Begriffen Erfüllung, Abtretung, Fälligkeit, Stundung, Einrede und Einwendung . . . . . . . . 59

Nr. 36 Arglistige Täuschung . . . . . . . . . . . . . . . $\quad$. 62

Nr. 37 Täuschung durch Dritte; Kausalität; Fahrlässigkeit . . . . 64

Nr. 38 Wegfall der Geschäftsgrundlage; Abgrenzung von Werkvertrag, Werklieferungsvertrag und Dienstvertrag . . . . . . . 67

Nr. 39 Vertragsanpassung bei Wegfall der Geschäftsgrundlage . . . 70

Nr. 40 Versteckter Dissens . . . . . . . . . . . . . 70

Nr. 41 Offener Dissens . . . . . . . . . . . . . . 71

Teil 6: Bedingungen. . . . . . . . . . . . . . 73

Nr. 42 Zu den Begriffen Bedingung, Frist, Termin, Vertrag zu Gunsten Dritter und Auflage . . . . . . . . . . . . 73

Nr. 43 Eigentumsvorbehalt als aufschiebende Bedingung . . . . 75

Nr. 44 Auflösende Bedingung . . . . . . . . . . . 75

Nr. 45 Schadensersatzpflicht des bedingt Berechtigten . . . . . 76

Nr. 46 Zwischenverfügungen; Verpflichtungs- und Verfügungsgeschäft . 76

Teil 7: Gesetzliche und rechtsgeschäftliche Vertretung . . . . . 79

Nr. 47 Die gesetzliche Vertretungsmacht der Eltern . . . . . . 79

Nr. 48 Vollmacht, Form; Innen- und Außenverhältnis . . . . . . 80

Nr. 49 Bote . . . . . . . . . . . . . . . . 82

Nr.50 Geschäftsführungs- und Vertretungsmacht; Gesamtvertretungsmacht . . . . . . . . . . . . . . . 82

Nr.51 Einzelvertretungsmacht . . . . . . . . . . . 84

Nr. 52 Prokura, Filiale, Vollkaufmann . . . . . . . . . 85

Nr. 53 Geschäftsführungs- und Vertretungsmacht des Prokuristen . . 87

Nr. 54 Form der Prokuraerteilung, Handlungsvollmacht, Handelsregister 88

Nr. 55 Handlungsgehilfe . . . . . . . . . . . . . 91

Nr. 56 Willensmängel des Vertreters . . . . . . . . . . 91

Nr. 57 Duldungsvollmacht . . . . . . . . . . . . . . 99

Nr. 58 Vollmacht und Innenverhältnis . . . . . . . . . . 93

Nr. 59 Anscheinsvollmacht; Haftung aus veranlaßtem Rechtsschein . . 93

Nr. 60 Gesamtvollmacht; Vertreter ohne Vertretungsmacht . . . . 95

Nr. 61 Untervollmacht; Einwilligung und Genehmigung . . . . . 96

Nr.62 Einseitige Rechtsgeschäfte ohne Einwilligung des gesetzlichen Vertreters . . . . . . . . . . . . . . 97

Nr. 63 Einseitige Gestaltungsgeschäfte des Vertreter ohne Vollmacht . 98 
Nr. 64 Treuhandverhältnisse; Begriffe aus der ZPO: Partei, Zeuge, Aussageverweigerungsrechte . . . . . . . . . . . 98

Nr.65 Strohmann . . . . . . . . . . . . . . . . 101

Nr.66 Inkassoermächtigung, Nichtberechtigter . . . . . . . 102

Nr.67 Ende der Vollmacht . . . . . . . . . . . . 103

Nr. 68 Haftung des Vertreters ohne Vertretungsmacht . . . . . 104

Nr. 69 wie vor . . . . . . . . . . . . . . . 104

Nr. 70 Widerruf . . . . . . . . . . . . . . . 105

Nr.71 Selbstkontrahieren . . . . . . . . . . . . 106

Nr. 72 Selbstkontrahieren, Doppelvollmacht . . . . . . . . 107

Nr. 73 Verfügung des Nichtberechtigten . . . . . . . . . 108

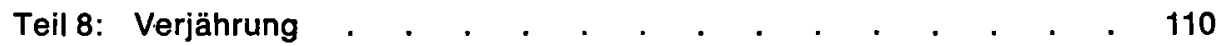

Nr. 74 Begründung und Entstehung eines Anspruchs . . . . . . 110

Nr. 75 Unterbrechung der Verjährung; Grundsätzliches zum Mahnverfahren, zur Klageerhebung und zum Armenrecht . . . . . . 111

Nr.76 Vollstreckungsbefehl . . . . . . . . . . . . 118

Nr.77 Hemmung der Verjährung; Stundung . . . . . . . . 118

Nr. 78 Beachtung der Verjährungseinrede im Prozeß . . . . . 119

Nr.79 Verlängerung und Verkürzung der Verjährungsfrist . . . . 120

Nr. 80 Verzicht auf Verjährungseinrede . . . . . . . . . 120

Stichwortverzeichnis . . . . . . . . . . . . . . . 121 
